\title{
Process-based analysis of relative contributions to the multi-model warming projection over East Asia
}

\author{
Hanjie Fan ${ }^{1} \cdot$ Xiaoming Hu$^{1,2,3}$ (1) $\cdot$ Song Yang ${ }^{1,2,3} \cdot$ Yong-Sang Choi ${ }^{4,5} \cdot$ Yoon-Kyoung Lee ${ }^{5}$
}

Received: 28 April 2020 / Accepted: 28 December 2020 / Published online: 12 January 2021

(c) The Author(s) 2021

\begin{abstract}
Climate models predict that East Asia (EA) will be substantially warmer than the present despite large inter-model uncertainty. This study investigated the major sources of the climate projections and the inter-model uncertainty. Particularly, we decomposed the differences in surface temperatures between the historical and RCP8.5 runs from 26 CMIP5 into partial surface temperature changes due to individual radiative and non-radiative processes through the climate feedback-response analysis method. Results show that anthropogenic greenhouse forcing and subsequent water vapor feedback processes are primarily responsible for the surface warming over EA. Relatively more rapid warming over the snow/ice-covered area and southern China is due to feedback processes associated with surface albedo and cloud, respectively. The regional warming is, however, compensated by the surface non-radiative (sensible and latent heat) cooling. The inter-model projection uncertainty is substantially large over high latitudes and the Tibetan Plateau mainly due to surface albedo feedback. Again, this large uncertainty is partly suppressed by surface non-radiative cooling. Water vapor and cloud feedbacks are the secondary important sources of the projection uncertainty. Moreover, the contributions of greenhouse forcing and atmospheric dynamics to the projection uncertainty are found to be minor.
\end{abstract}

Keywords East Asia $\cdot$ Surface warming projection $\cdot$ RCP8.5 scenario $\cdot$ Uncertainty of model projection $\cdot$ Climate feedback

\section{Introduction}

Anthropogenically-induced temperature warming has been documented to bring about increasing risks of extreme weather and climate events globally (Diffenbaugh et al. 2015; Yuan et al. 2019). However, the magnitude of surface warming response to increased atmospheric greenhouse gas concentrations (GHGs) is still uncertain, especially for the

Xiaoming $\mathrm{Hu}$

huxm6@mail.sysu.edu.cn

1 School of Atmospheric Sciences, Sun Yat-sen University, Guangzhou 510275, Guangdong, China

2 Southern Marine Science and Engineering Guangdong Laboratory (Zhuhai), Zhuhai, China

3 Guangdong Province Key Laboratory for Climate Change and Natural Disaster Studies, Sun Yat-Sen University, Zhuhai, China

4 Department of Climate and Energy Systems Engineering, Ewha Womans Universtiy, Seoul, South Korea

5 Center for Climate/Environmental Change Prediction Research, Ewha Womans University, Seoul, South Korea densely populated areas such as East Asia (EA), South Asia and the Middle East (Fischer and Knutti 2015; Byers et al. 2018; Lee and Min 2018). In general, the uncertainty of climate projection is greater at the regional scale than at the global scale, and the sources of regional climate projection uncertainty are different from those of the global scale (Giorgi 2010).

EA is one of the most vulnerable regions to climate change as it has large climate fluctuations as well as high population density and socioeconomic importance (Xin et al. 2013). In the last few decades, EA has experienced a warming trend (Chen et al. 2018), associated with which are more frequent and stronger abnormal weather or climate phenomena, including severe summer heat waves, enhanced precipitation, extensive droughts, pronounced winter warming, and excessive melting of snow packs in high terrains (Serreze et al. 2000; Yang et al. 2002; Li et al. 2010; Romanovsky et al. 2010; Zhu et al. 2011; Wang et al. 2014; Christensen et al. 2013; Min et al. 2015). The climate change projections by general circulation models (GCMs) from different research institutions (e.g., the phase 5 of the Coupled Model Intercomparison Project, CMIP5; Taylor 
et al. 2012) generally show that EA will continue warming with a much greater amplitude than the global mean (Jiang et al. 2004; Min et al. 2006; Baek et al. 2013; Collins et al. 2013). Risks of natural hazards, like heavy rains, droughts, and heat waves, are also projected to increase over EA (Chen et al. 2012; Qu et al. 2014; Wang et al. 2014; Ji and Kang 2015; Yuan et al. 2019). The adverse potential future climate changes call for a more urgent need for governments to enact adaptation/mitigation strategies for coping with the continued rapid warming trend. However, larger warming projections come with larger uncertainty, which brings about further difficulties in making policies and decisions for adaptation/mitigation.

Among the previous works dedicated to reduce the uncertainty of climate change over EA, Shukla et al. (2006) argued that the models with better performance of current climate simulation could make more reliable projection. However, Heo et al. (2014) and Seo et al. (2014) found that the assessment of model performance in current climate states depends on the variables considered (e.g. relative entropy and probability density function) and the methods applied (e.g. signal-to-noise ratio analysis and empirical orthogonal function analysis). Thus, it is still challenging to obtain a credible climate projection by statistical analysis methods. Recently, climate radiative feedback methods have been broadly used to investigate the uncertainties in global warming and polar amplification (Colman 2003; Lu and Cai 2010; Vial et al. 2013; Pithan and Mauritsen 2014; Hu et al. 2020). The advantage of the climate feedback method is that the uncertainty of climate feedback can be identified, allowing us to reveal the major sources of the uncertainty of climate change projections. At present, there is a lack of comprehensive studies focusing on the EA region; thus specifically, systematical and quantitative investigations of the sources of surface warming magnitude in the future and the warming projection uncertainty (WPU) over EA are of vital importance.

To reveal the major sources of warming projections and their uncertainty over EA, the contributions of individual feedback processes to the future warming projection and their uncertainty are calculated by conducting a processbased decomposition of the projected surface warming over EA, which is referred to as the differences in land surface temperatures between the historical and future climate states. The climate feedback method that we apply is the coupled atmosphere-surface climate feedback-response analysis method (CFRAM; Lu and Cai 2009; Cai and Lu 2009), which characterizes the contributions of individual feedback processes to the projected surface warming by partial surface temperature changes due to individual radiative (e.g., albedo, water vapor, cloud, greenhouse gases, and ozone) and nonradiative (surface heat fluxes and heat transport) feedback processes. The CFRAM has been adopted to quantify temperature anomalies associated with inter-annual climate variabilities (El Niño, Hu et al. 2016, 2018; Northern Annular Mode, Deng et al. 2013), polar amplification (Lu and Cai 2010), seasonality of surface warming (Sejas et al. 2014) and surface temperature bias in climate models (Park et al. 2013; Chen et al. 2017). More recently, it was applied to diagnose the observed warming between early 2000s and early 1980s as well as the year-to-year temperature fluctuations over EA based on the ERA Interim reanalysis (Chen et al. 2018).

The main goal of this paper is to present a process-based feedback analysis to document the main factors responsible for the future warming projections and their uncertainty over East Asia. The paper is organized as follows. Section 2 describes the CMIP5 data sets and the CFRAM method that we apply. Section 3 compares the MME mean warmings over EA and all land surfaces of the globe. The result supplements previous findings (e.g., Jiang et al. 2004; Min et al. 2006; Baek et al. 2013; Collins et al. 2013; Taylor et al. 2012; and Xu et al. 2017), which show that the warming over EA is also stronger than the mean warming over all land surfaces. We here further document that it is mainly a strong surface albedo feedback that leads to the strong warming over EA, as far as the MME is concerned. In Sect. 4, we examine the main factors for the spatial difference in the projected warming within the EA region. Section 5 is focused on the sources of the WPU over EA, namely the main factors for the inter-model spread of the areal mean warming and its spatial patterns. Conclusions are given in Sect. 6.

\section{Data and method}

Monthly mean outputs from the historical and RCP8.5 model simulations produced by the Coupled Model Intercomparison Project Version 5 (CMIP5; Taylor et al. 2012) are used to diagnose global warming amplitude. All the CMIP5 data used are archived and are freely accessible at http://data.ceda. ac.uk/badc/cmip5/data/cmip5/ and https://esgf-node.llnl.gov/ search/cmip5/. The variables considered in CFRAM include temperature, specific humidity, ozone mixing ratio, cloud cover, cloud liquid/ice water content, downward shortwave energy flux at the top of the atmosphere, surface albedo, and surface sensible and latent heat fluxes. Twenty-six CMIP5 model possess all the variables required by the CFRAM analysis. Table 1 lists those 26 model simulations in the order of area-averaged land surface warming amplitude in East Asia. The historical and future climate states are evaluated for the 50-year means of 1951-2000 in historical simulations and the period of 2051-2100 in the RCP8.5 simulations, respectively. The difference in land surface temperature between the future and historical climate states of each model corresponds to the global warming projection of the specific model. The WPU 
Table 1 A list of CMIP5 models analyzed and their projected mean surface temperature change $(<\Delta T>$ ) over East Asia (EA), defined as the difference between historical run (the mean of 1951-2000) and RCP8.5 (the mean of 2051-2100) experiments

\begin{tabular}{|c|c|c|c|c|}
\hline No & Model acronym & Institution & $<\Delta T>$ & $<\Delta T^{*}>$ \\
\hline 1 & GFDL-CM3 & NOAA-Geophysical Fluid Dynamics Laboratory & 6.68 & 1.72 \\
\hline 2 & FGOALS-s2 & $\begin{array}{l}\text { LASG, Institute of Atmospheric Physics, Chinese Academy of Sciences and CESS, Tsinghua } \\
\text { University }\end{array}$ & 6.37 & 1.41 \\
\hline 3 & CanESM2 & Canadian Centre for Climate Modelling and Analysis & 6.27 & 1.31 \\
\hline 4 & BNU-ESM & College of Global Change and Earth System Science, Beijing Normal University & 6.1 & 1.14 \\
\hline 5 & IPSL-CM5A-LR & Institute Pierre-Simon Laplace & 5.87 & 0.91 \\
\hline 6 & IPSL-CM5A-MR & Institute Pierre-Simon Laplace & 5.87 & 0.91 \\
\hline 7 & CESM1-CAM5 & NSF, Department of Energy, and National Center for Atmospheric Research & 5.6 & 0.64 \\
\hline 8 & CMCC-CMS & Centro Euro-Mediterraneo per I Cambiamenti Climatici & 5.42 & 0.46 \\
\hline 9 & CMCC-CM & Centro Euro-Mediterraneo per I Cambiamenti Climatici & 5.37 & 0.41 \\
\hline 10 & NorESM1-ME & Norwegian Climate Centre & 5.3 & 0.34 \\
\hline 11 & NorESM1-M & Norwegian Climate Centre & 5.13 & 0.17 \\
\hline 12 & CCSM4 & National Center for Atmospheric Research & 4.99 & 0.03 \\
\hline 13 & MPI-ESM-LR & Max Planck Institute for Meteorology & 4.88 & -0.08 \\
\hline 14 & CMCC-CESM & Centro Euro-Mediterraneo per I Cambiamenti Climatici & 4.87 & -0.09 \\
\hline 15 & CESM1-BGC & NSF, Department of Energy, and National Center for Atmospheric Research & 4.71 & -0.25 \\
\hline 16 & MPI-ESM-MR & Max Planck Institute for Meteorology & 4.69 & -0.27 \\
\hline 17 & MIROC5 & $\begin{array}{l}\text { The University of Tokyo, National Institute for Environmental Studies, and Japan Agency for } \\
\text { Marine-Earth Science and Technology }\end{array}$ & 4.64 & -0.32 \\
\hline 18 & IPSL-CM5B-LR & Institute Pierre-Simon Laplace & 4.59 & -0.37 \\
\hline 19 & bcc-csm1-1 & Beijing Climate Center & 4.55 & -0.41 \\
\hline 20 & CSIRO-Mk3.6.0 & CSIRO in collaboration with Queensland Climate Change Centre of Excellence & 4.41 & -0.55 \\
\hline 21 & FGOALS-g2 & $\begin{array}{l}\text { LASG, Institute of Atmospheric Physics, Chinese Academy of Sciences and CESS, Tsinghua } \\
\text { University }\end{array}$ & 4.09 & -0.87 \\
\hline 22 & MRI-CGCM3 & Meteorological Research Institute & 3.96 & -1.00 \\
\hline 23 & GFDL-ESM2G & NOAA-Geophysical Fluid Dynamics Laboratory & 3.81 & -1.15 \\
\hline 24 & GISS-E2-H & NASA-Goddard Institute for Space Studies & 3.72 & -1.24 \\
\hline 25 & GFDL-ESM2M & NOAA-Geophysical Fluid Dynamics Laboratory & 3.68 & -1.28 \\
\hline 26 & GISS-E2-R & NASA-Goddard Institute for Space Studies & 3.33 & -1.63 \\
\hline
\end{tabular}

$\left\langle\Delta T^{*}\right\rangle$ is the warming projection spread or the departure of $\langle\Delta T>$ of individual models from the multi-model ensemble mean. Numbers in the first column indicate the rankings of models in areal mean surface warming over EA

is calculated as the range of deviations of the 26 models from the MME.

The individual contribution of each radiative or non-radiative feedback process to the global warming amplitude is calculated by the CFRAM via decomposing the total warming into partial surface temperature changes due to individual climate processes (Cai and Lu 2009; Lu and Cai 2009). The CFRAM is based upon the total energy balance in an atmosphere-surface column that consists of multiple atmospheric layers and the surface layer. The difference () in the energy balance equation between the current and future climate states is written as follows:

$\frac{\Delta(\partial \vec{E})}{\partial t}=\Delta(\vec{S}-\vec{R})+\Delta \vec{Q}$ where $\frac{\Delta(\partial \vec{E})}{\partial t}$ is the difference in energy storage between the two states; $\Delta(\vec{S}-\vec{R})$ is the difference in vertical profiles of convergence of shortwave (denoted as $\vec{S}$ ) and divergence of longwave (denoted as $\vec{R}$ ) radiation fluxes within individual layers, corresponding to the vertical profile of changes in the net radiative heating rate; and $\Delta \vec{Q}$ represents the difference in vertical profiles of non-radiative heating rates, or the energy flux convergence due to dynamic processes. The surface layer component of $\Delta \vec{Q}$ over oceans corresponds to the changes in the net convergence of energy due to oceanic motions on all scales. While the surface layer component of $\Delta \vec{Q}$ over land/snow/ice surfaces represents the changes in the energy gain due to soil heat diffusion, runoff, and snow/ ice melting and freezing. 
Evoking linear approximation, $\Delta(\vec{S}-\vec{R})$ can be further decomposed into partial differences due to individual radiative feedback processes as follows:

$$
\begin{aligned}
\Delta(\vec{S}-\vec{R})= & \Delta(\vec{S}-\vec{R})^{\mathrm{EXT}}+\Delta \vec{S}^{\mathrm{AL}}+\Delta(\vec{S}-\vec{R})^{\mathrm{WV}} \\
& +\Delta(\vec{S}-\vec{R})^{\mathrm{CLD}}+\Delta(\vec{S}-\vec{R})^{\mathrm{O}_{3}}-\frac{\partial \vec{R}}{\partial \vec{T}} \Delta \vec{T}
\end{aligned}
$$

where the terms with superscripts "EXT", "AL", "WV", "CLD", and " $\mathrm{O}_{3}$ " correspond to, respectively, the partial radiative heating rate differences due to external forcing (e.g. $\mathrm{CO}_{2}, \mathrm{CH}_{4}$, and $\mathrm{N}_{2} \mathrm{O}$ ), the changes in surface albedo, water vapor, clouds, and ozone from the current to future climate states. The last term in (2), i.e. the product of $\frac{\partial \vec{R}}{\partial \vec{T}}$ and $\Delta \vec{T}$, is a further linearization of $\Delta \vec{R}^{\text {Temp }}$, the vertical profile of the partial radiative cooling rate difference due to the temperature difference between the two climate states in each atmospheric layer and at the surface (denoted as $\Delta \vec{T}$ ). The matrix $\frac{\partial \vec{R}}{\partial \vec{T}}$ is the Planck feedback matrix whose $j$ th column $\left(\frac{\partial \vec{R}}{\partial T_{j}}\right)$ measures the vertical profile of changes in longwave radiative energy flux due to $1 \mathrm{~K}$ warming in the $j$ th layer alone $\left(\Delta T_{j}=1 K\right)$.

By substituting (2) into (1) and re-arranging the terms, we obtain

$$
\begin{aligned}
\Delta \vec{T}= & \left(\frac{\partial \vec{R}}{\partial \vec{T}}\right)^{-1}\left\{\Delta(\vec{S}-\vec{R})^{\mathrm{EXT}}+\Delta \vec{S}^{\mathrm{AL}}+\Delta(\vec{S}-\vec{R})^{\mathrm{WV}}\right. \\
& \left.+\Delta(\vec{S}-\vec{R})^{\mathrm{CLD}}+\Delta(\vec{S}-\vec{R})^{\mathrm{O}_{3}}+\Delta \vec{Q}-\Delta \frac{\partial \vec{E}}{\partial \vec{T}}\right\}
\end{aligned}
$$

The total temperature change can be separated into partial temperature changes due to each feedback process:

$$
\begin{aligned}
\Delta \vec{T}^{\mathrm{EXT}} & =\left(\frac{\partial \vec{R}}{\partial \vec{T}}\right)^{-1} \Delta(\vec{S}-\vec{R})^{\mathrm{EXT}} ; \Delta \vec{T}^{\mathrm{AL}}=\left(\frac{\partial \vec{R}}{\partial \vec{T}}\right)^{-1} \Delta \vec{S}^{\mathrm{AL}} ; \Delta \vec{T}^{\mathrm{WV}} \\
& =\left(\frac{\partial \vec{R}}{\partial \vec{T}}\right)^{-1} \Delta(\vec{S}-\vec{R})^{\mathrm{WV}} ; \Delta \vec{T}^{\mathrm{CLD}}=\left(\frac{\partial \vec{R}}{\partial \vec{T}}\right)^{-1} \Delta(\vec{S}-\vec{R})^{\mathrm{CLD}} ; \Delta \vec{T}^{\mathrm{O}_{3}} \\
& =\left(\frac{\partial \vec{R}}{\partial \vec{T}}\right)^{-1} \Delta(\vec{S}-\vec{R})^{\mathrm{O}_{3}} ; \text { and } \Delta \vec{T}^{\mathrm{non} \_ \text {rad }}=\left(\frac{\partial \vec{R}}{\partial \vec{T}}\right)^{-1}\left(\Delta \vec{Q}-\Delta \frac{\partial \vec{E}}{\partial \vec{T}}\right)
\end{aligned}
$$

The first five equations in (4) can be readily solved since $\left(\frac{\partial \vec{R}}{\partial T_{j}}\right)$ and the partial radiative heating/cooling rate differences can be calculated individually via linearization of a radiative transfer model. As for the non-radiative term (the term with superscript "non_rad"), we separate its right hand $\operatorname{side}\left(\Delta \vec{Q}-\Delta \frac{\partial \vec{E}}{\partial \vec{T}}\right)$ into surface and atmospheric components, denoted as $\Delta \vec{Q}^{\mathrm{ATM}}$ and $\Delta \vec{Q}^{\mathrm{SRF}}$. The term $\Delta \vec{Q}^{\mathrm{SRF}}=0$ in all atmospheric layers and at the surface layer, it is
$\left(\Delta \vec{Q}^{\mathrm{SRF}}\right)_{\text {surf }}=-\Delta Q^{\mathrm{LH}}-\Delta Q^{\mathrm{SH}}+\Delta \vec{Q}^{\mathrm{DYN} \_ \text {Storage }}$

where $\Delta Q^{\mathrm{LH}}$ and $\Delta Q^{\mathrm{SH}}$ are surface cooling rate differences due to the changes in surface turbulent sensible and latent heat fluxes (whose sign convention is positive for upward), while the sum of surface dynamics and energy storage terms $\left(\Delta \vec{Q}^{\text {DYN_Storage }}\right)$ is estimated as the residual of the surface energy balance equation, i.e.,

$\Delta \vec{Q}^{\text {DYN_Storage }}=-\Delta(\vec{S}-\vec{R})_{\text {surf }}+\Delta Q^{\mathrm{LH}}+\Delta Q^{\mathrm{SH}}$

In the atmospheric layers, $\Delta \vec{Q}^{\mathrm{ATM}}=\Delta \vec{Q}=-\Delta(\vec{S}-\vec{R})$, after evoking the assumption that the atmospheric storage term is zero and in the surface layer, $\Delta \vec{Q}^{\mathrm{ATM}}=0$. In other words, $\Delta \vec{Q}^{\mathrm{ATM}}$ represents changes in the energy flux convergence in each atmospheric layer at a given location due to the energy transport by all scales of atmospheric motions.

In practice, we adopt the Fu-Liou radiative transfer model (Fu and Liou 1992, 1993) to evaluate each radiative heating term on the righthand side of Eq. (3). Take $\Delta(\vec{S}-\vec{R})^{\mathrm{WV}}$ as an example, the "off-line" radiative transfer calculation is conducted separately for base state "A" (historical simulations) and perturbed state "B" (RCP8.5 simulations) where all the atmospheric/surface properties are kept the same as in climate state " $\mathrm{A}$ " except that the vertical profile of atmospheric water vapor is replaced with its counterpart in climate state " $B$ ". Then the net radiative heating difference between the perturbed state and the base state represents the difference due to the change in atmospheric water vapor alone, namely, $\Delta(\vec{S}-\vec{R})^{\mathrm{WV}}$.

In short, Eq. (3) enables us to calculate, grid by grid, the vertical profiles of partial temperature differences due to external forcing and changes in surface albedo, water vapor, cloud, ozone, atmospheric dynamics (i.e. energy transport by all-scale atmospheric motions), and surface non-radiative heat perturbation (including surface dynamics, sensible heat flux, and latent heat flux). The agreement between the sum of these partial temperature differences with the total temperature differences derived from the original CMIP5 RCP8.5 simulations is a good indicator of the robustness of our quantifying contributions to the projected temperature differences from various climate processes. In this paper, we focus on the surface components of these partial temperature perturbation fields over the land surface in EA $\left(15^{\circ}-70^{\circ} \mathrm{N}\right.$, $70^{\circ}-160^{\circ} \mathrm{E}$ ), which are referred to as partial surface temperature changes. The contributions of future warming from various climate processes will be revealed by the MME of partial surface temperature changes. Moreover, the sources of warming uncertainty will be investigated via comparing the inter-model spreads of partial surface temperature changes. 


\section{Comparison of the areal mean warming over EA with that over all land surfaces}

Figure 1a shows the areal mean land warming projections over the globe (blue bars) and EA (orange bars) simulated by 26 CMIP5 models (ordered by their warming amplitudes over EA), with MME results and inter-model spreads (one standard deviation) at the right end. The warming projections over EA by all models are clearly greater than those over all land areas of the globe. This result supplements the finding by previous studies (e.g., Jiang et al. 2004; Min et al. 2006; Baek et al. 2013; Collins et al. 2013; Taylor et al. 2012; and Xu et al. 2017), which show that the warming over EA is also stronger than the mean warming over all land areas, in addition to the global mean warming. As listed in Table 1, the range of area-mean surface warming over EA is from 3.33 to $6.68 \mathrm{~K}$, which is larger than the global land-area mean warming of $3.18-5.62 \mathrm{~K}$.
We have applied the CFRAM analysis to the output from each model separately. Specifically, we obtain the seven terms of CFRAM-derived partial surface temperature differences due to the external forcing and individual internal feedback processes for each model, according to Eqs. (4) and (6). The sum of these partial surface temperature differences (colored bars in Fig. 1b) is close to the total temperature change as recorded in the original simulations (hatched bars in Fig. 1b), suggesting that the CFRAM is able to decompose the total temperature change reliably.

Based on the results of CFRAM analysis for each model (Fig. 2) and their MME (Fig. 1b), the common feature of the area-mean surface warming over EA and the globe is that the warming can be largely attributed to anthropogenic greenhouse gases and positive water vapor feedback, and further amplified by surface albedo feedback and cloud feedback. Ozone and atmospheric dynamics process exert little impacts on temperature change and surface non-radiative processes suppress the warming amplitude.

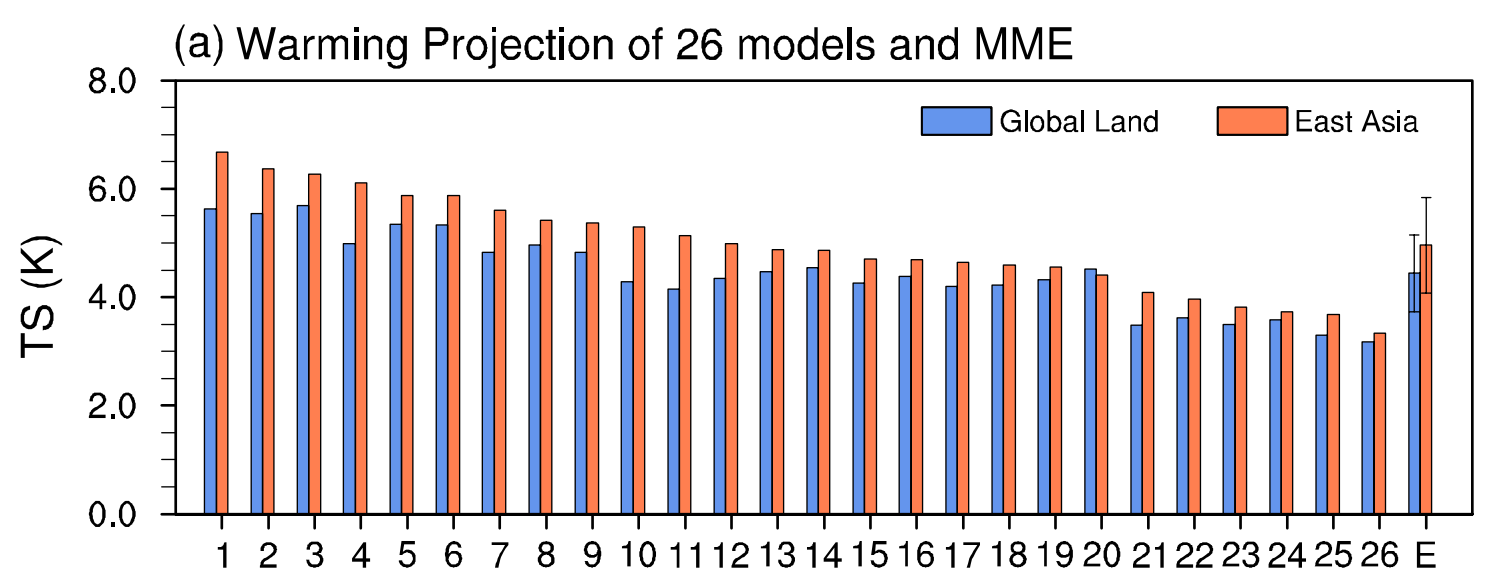

(b) MME of Process-based Decomposition of (a)

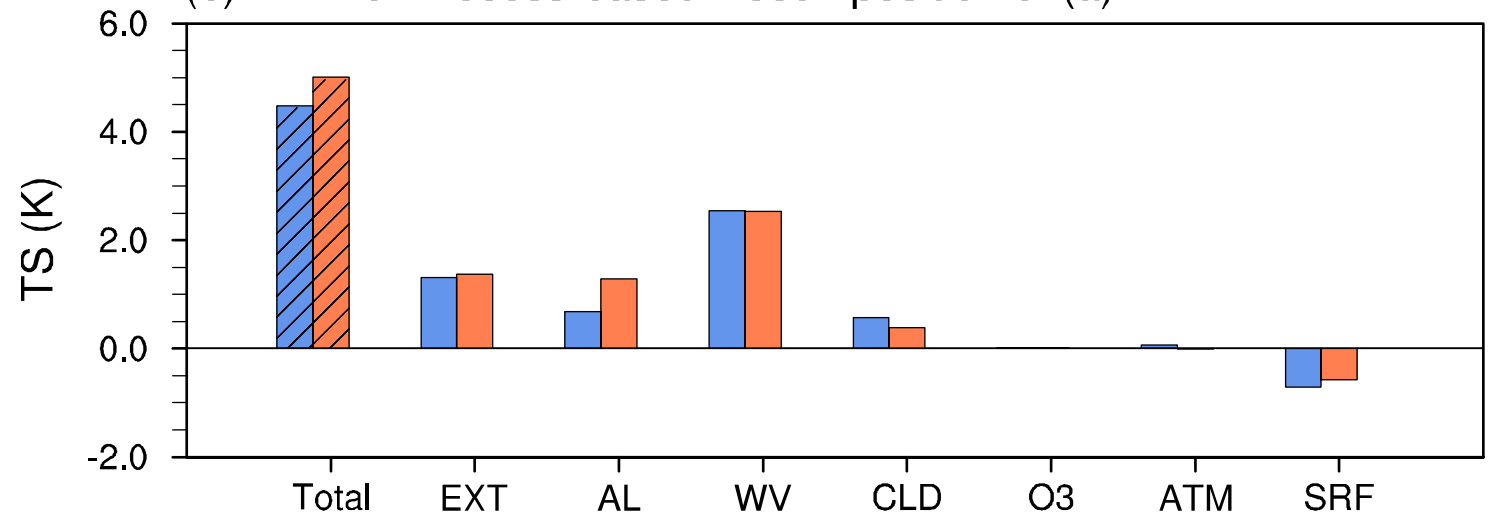

Fig. 1 a Differences in area-mean surface temperature $(K)$ between historical and RCP8.5 scenario simulations from 26 models for land surface over the globe (blue bars) and EA (orange bars), ordered by warming amplitudes over EA (see details in Table 1). Values of multi-model ensemble mean (MME, "E" in short) are shown at the right end. b MME values of partial temperature changes due to individual external forcing and climate feedback processes for the over globe and EA 


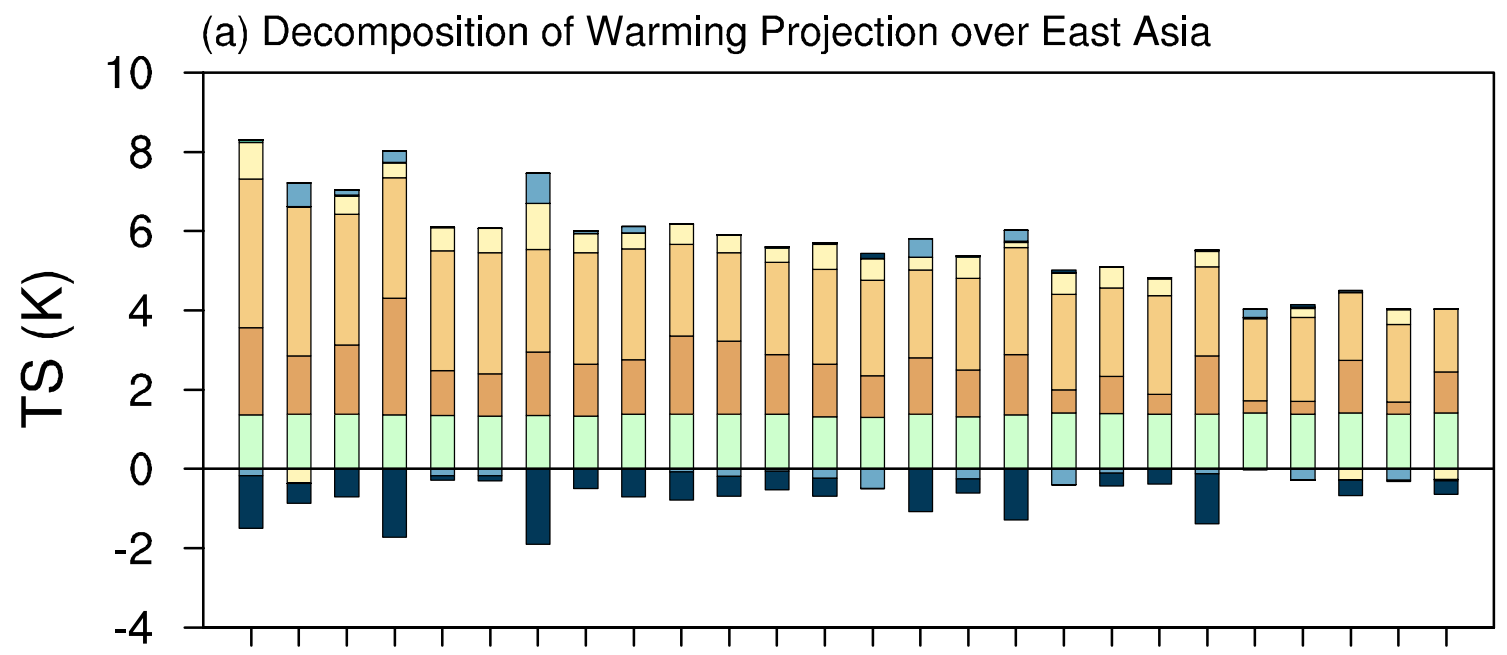

(b) Decomposition of Warming Projection over Global Land

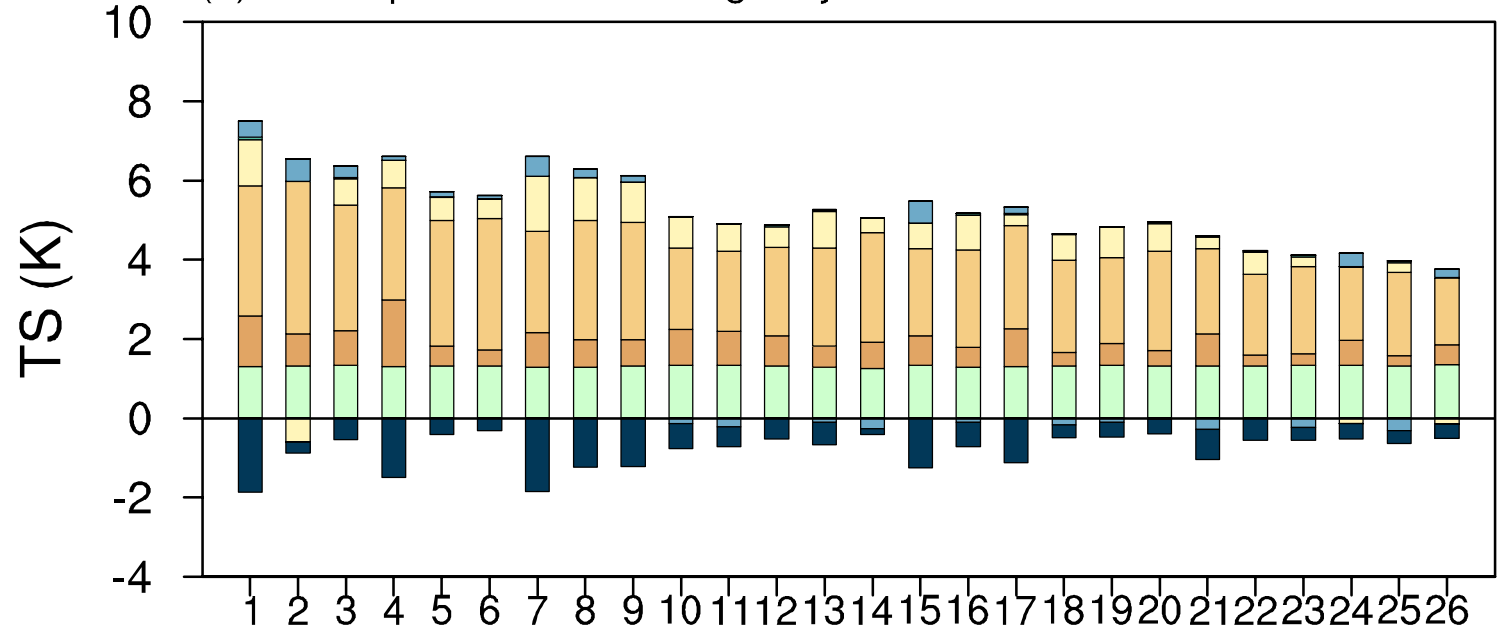

$\square$ EXT $\square$ AL $\square$ WV $\square$ CLD $\square$ O3 $\square$ ATM $\square$ SRF

Fig. 2 Decompositions of surface warming $(K)$ under the RCP8.5 scenario over a EA and $\mathbf{b}$ global land surface into partial surface temperature changes due to individual external forcing and feedbacks for each model

The area-mean contributions of each process to the surface warming are different over EA and the globe in magnitudes, although their signs (positive or negative) are mostly identical (Figs. 1b, 2). Most importantly, the surface albedo feedback produces a larger warming over EA compared with the global land-mean value, meanings that the decrease in area-mean surface albedo is stronger over EA than the global land areas. In addition, the mean cooling effect due to surface non-radiative processes is slightly weaker over EA than the global land areas. The combined effect of surface albedo feedback and non-radiative processes is responsible for the stronger warming over EA than the global land areas.

\section{Spatial patterns of the MME warming projection over East Asia}

Considering the spatial complexity of EA, we further examine the spatial patterns of MME results about surface temperature warming (contours in Fig. 3a) and the individual partial temperature change due to each feedback process derived from the CFRAM (Fig. 3b-i). The sum of partial temperature changes (shadings in Fig. 3a) resembles the surface warming pattern, which validates the CFRAM-based attribution to the total warming pattern.

Surface warming is most pronounced over the high latitudes (Siberia) and the high-elevation areas (central Asia and the Tibetan Plateau) in the northwest of EA. The anthropogenic greenhouse forcing causes uniform warming 


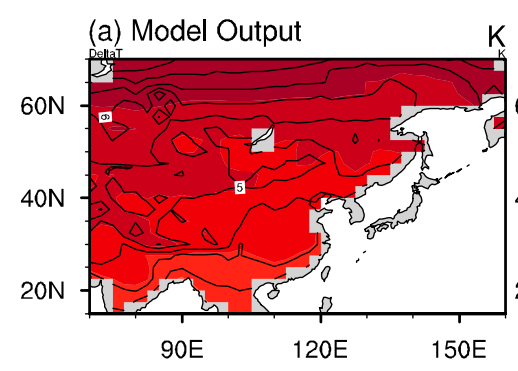

(d) WV

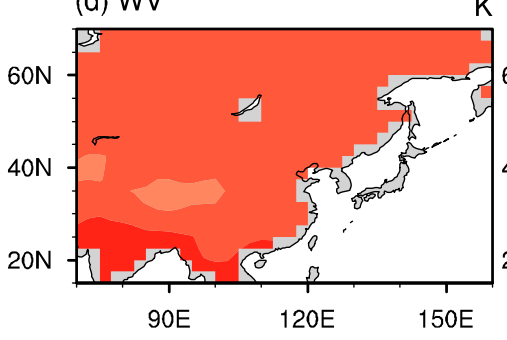

(g) ATM

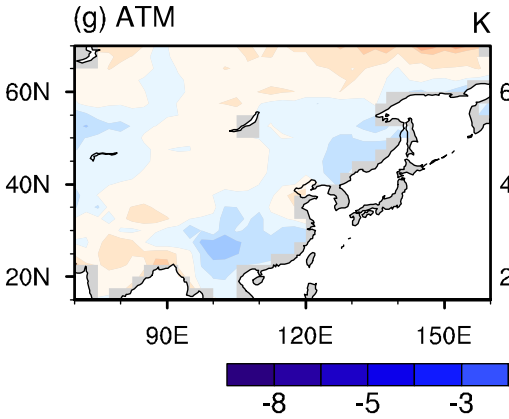

(b) EXT

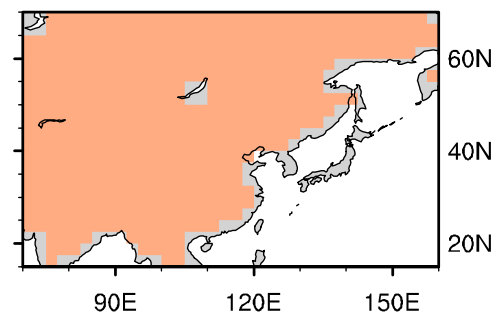

(e) CLD

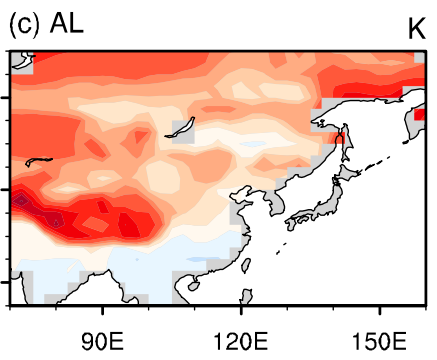

(f) $\mathrm{O} 3$

K

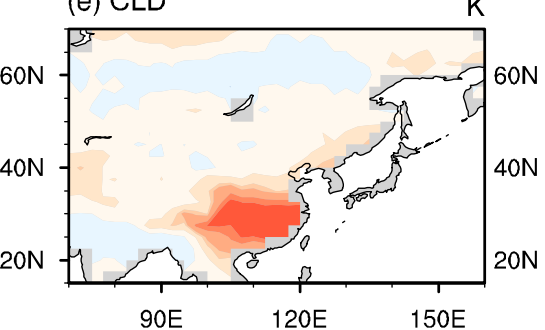

(h) SRF

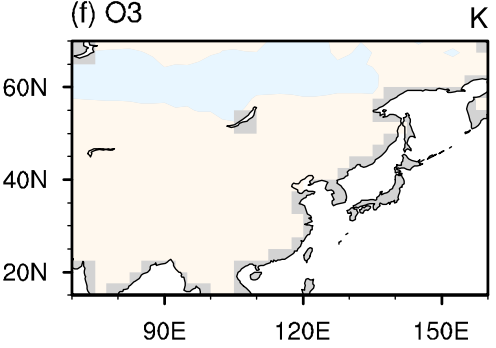

5

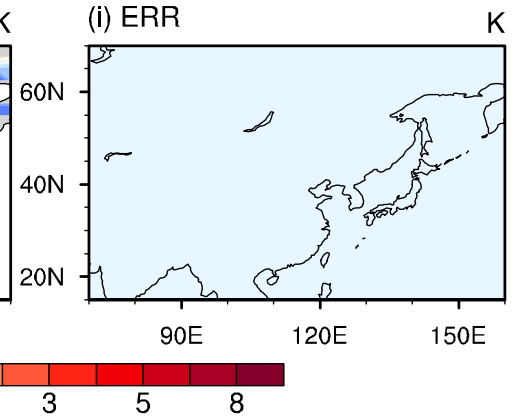

Fig. 3 Spatial patterns of MME of surface temperature changes $(K)$ over EA: model output (contour) and the sum of partial temperature differences derived from the CFRAM (shading) (a), and the partial temperature changes due to external forcing (b), albedo (c), water vapor (d), cloud (e), ozone (f), atmospheric dynamic process (g), and surface dynamic process (e.g. surface sensible and latent heat fluxes) (h). The error term shown in (i) is the difference between model output and CFRAM-derived total temperature difference over EA with areal mean warming amplitude of $1.37 \mathrm{~K}$ (Fig. 3b). Surface albedo changes in the future are resulted from decreasing ice/snow covers, and therefore warming is mainly located in the snow/ice-covered regions, i.e. the high-latitude and plateau regions, especially the southern Tibetan Plateau (Figs. 3c, 4a). Because of the extremely high altitudes, there are more snow/ice surfaces over the Tibetan Plateau than other regions with similar latitudes. Therefore, there will be more melting of snow/ice, causing a reduction of snow/ice covered surface in the warming scenario over the Tibetan Plateau, and thus more pronounced decrease in surface albedo over EA than the globe.

Under the RCP8.5 scenario, there will be more atmospheric water vapor over the whole EA (Fig. 4b), as reported by previous studies (Xu et al. 2017; Xu and Fan 2019). Thus, the increase in water vapor content enhances downward longwave radiation, causing a relatively uniform warming pattern and making the greatest positive contribution (Fig. 3d, $2.53 \mathrm{~K}$ ). The warming associated with water vapor shows a weak northward descending gradient with a maximum over South Asia and the Indo-China Peninsula, matching well with the MME pattern of increase in total column water vapor shown in Fig. 4b.

The cloud effect makes significant contributions only over southern China (Fig. 3e), where both cloud fraction and column integrated cloud liquid/ice water are projected to decrease (Fig. 4c, d). According to Xin et al. (2013), the reduction of cloud is attributed to the northward shifts of the jet stream and the corresponding prevalent ascending motion. In general, the direct effect in cloud changes strongly depends on the spatial distribution of the incoming solar energy flux. Over low latitudes, the cloud-albedoinduced changes of downward shortwave fluxes at the surface are expected to be stronger than their longwave effects because of the strong incoming solar energy flux. Hence, the decreased cloud cover and cloud water over southern China make positive contributions to the warming. On the other hand, the decrease in cloud fraction and increase in cloud water over the Tibetan Plateau counteract to each other, and make a less contribution to the warming.

Surface temperature changes due to surface non-radiative processes show a dipole pattern with warming in the 

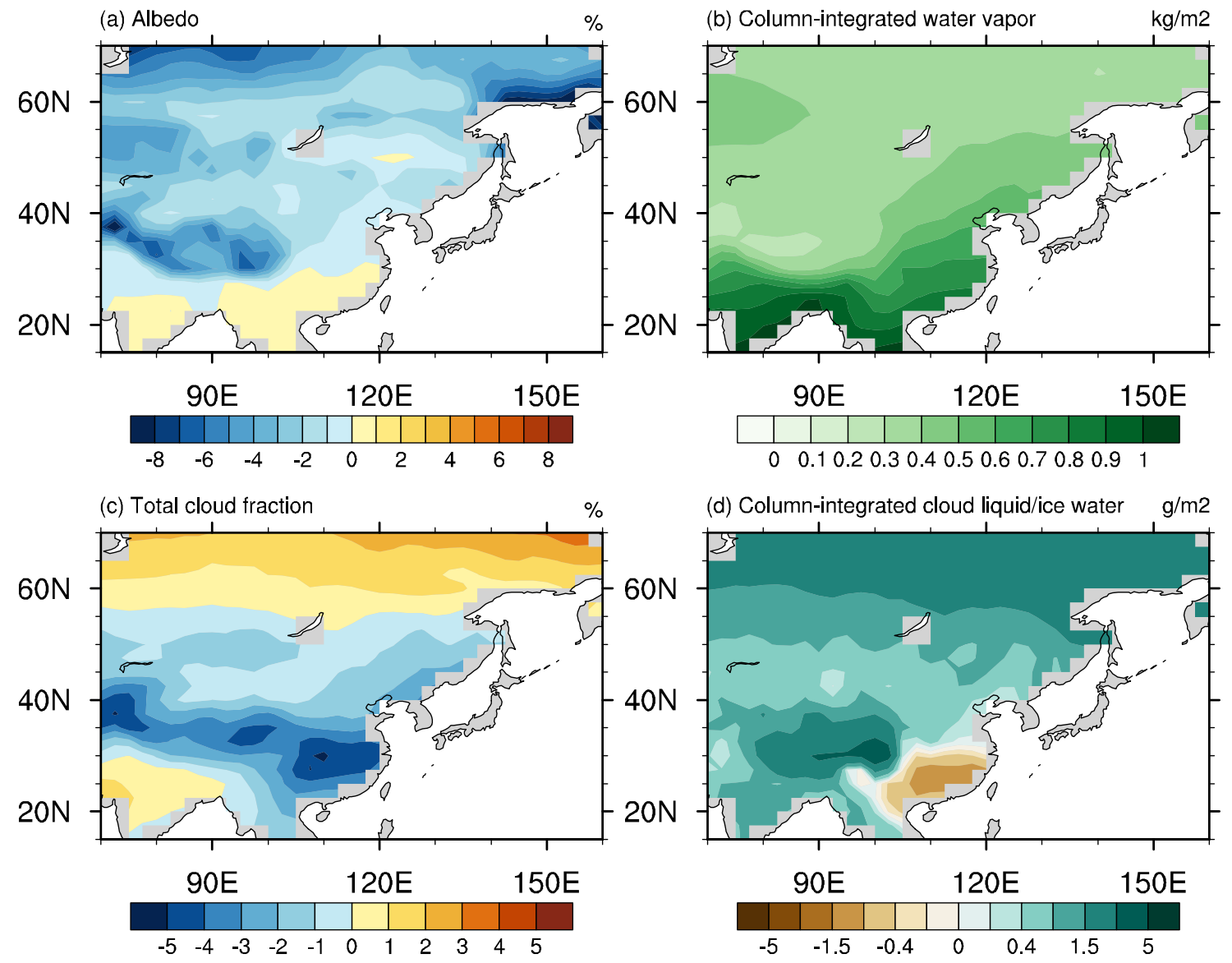

(d) Column-integrated cloud liquid/ice water $\mathrm{g} / \mathrm{m} 2$

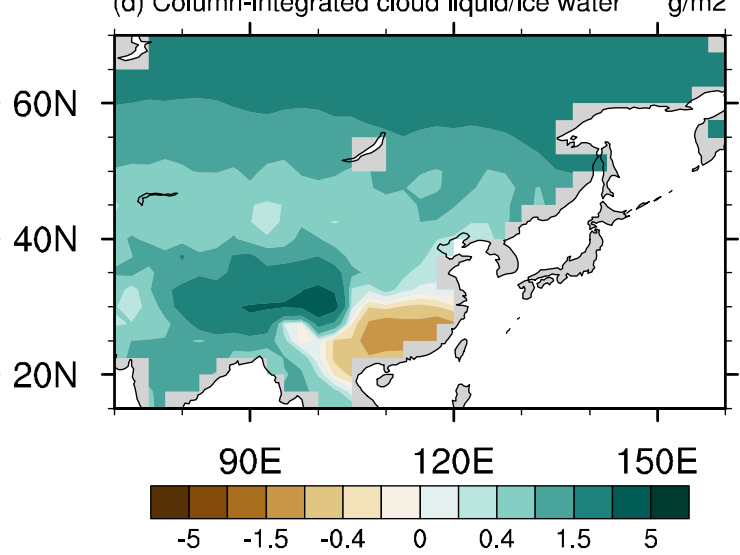

Fig. 4 Spatial patterns of MME changes in a surface albedo (\%), b total column-integrated water vapor content $\left(10^{-3} \mathrm{~kg} / \mathrm{m}^{2}\right)$, and $\mathbf{c}$ total cloud fraction (\%) and $\mathbf{d}$ column-integrated cloud liquid/ice water $\left(\mathrm{g} / \mathrm{m}^{2}\right)$ between historical and RCP8.5 simulations

north and cooling in the south. To some extent this pattern is opposite to the patterns of albedo and cloud terms, implying that surface non-radiative processes reduce the spatial non-uniformity induced by albedo and cloud feedbacks. The changes in ozone and atmospheric dynamics process make limited contributions (Fig. 3f, g).

Overall, under the RCP 8.5 scenario, the increase in anthropogenic greenhouse gases causes uniform surface warming over EA. In response to external forcing, water vapor feedback amplifies the initial warming significantly. Surface albedo and cloud feedbacks also contribute to EA surface warming positively, though less uniformly. Changes in surface heat fluxes mainly act to suppress the warming and reduce the spatial non-uniformity.

\section{Sources of WPU over East Asia}

\subsection{Areal mean WPU}

According to Table 1 and Fig. 1a, EA mean shows stronger surface warming and larger inter-model spread or WPU compared to the global and global-land surface mean. In this section, the source of WPU over EA will be revealed based on inter-model spreads of CFRAM-derived partial surface temperature changes.

Figure 5a provides an overall assessment of the uncertainties of EA-mean total and partial temperature changes by a box diagram. The inter-model spread of the total temperature change is about $3 \mathrm{~K}$. Surface albedo feedback, water vapor feedback, and surface non-radiative processes are the three terms with significant model uncertainties. Cloud feedback and atmospheric dynamics display relatively smaller fluctuations, and nearly no inter-model spreads exist in terms of external forcing and ozone. The 


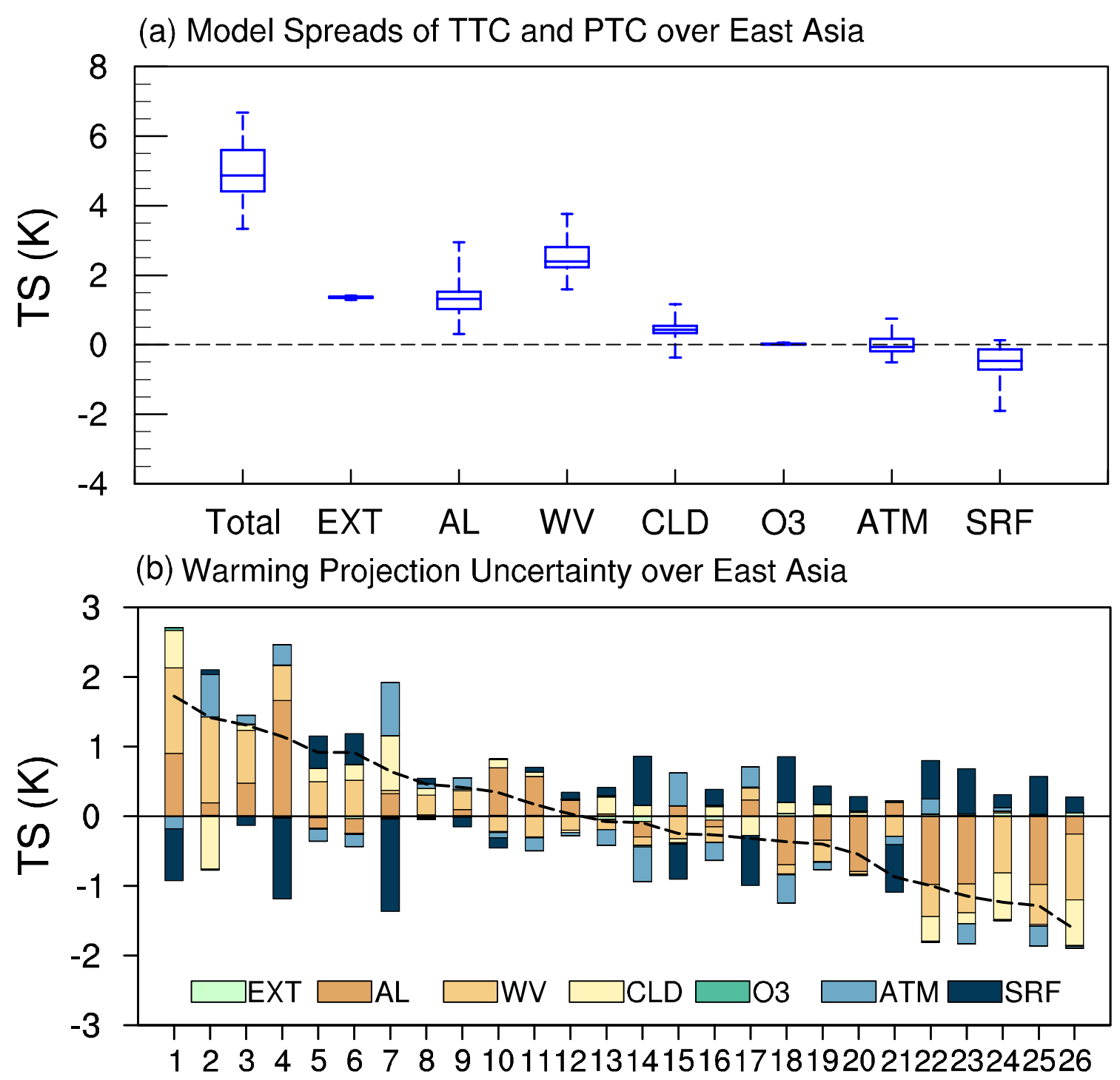

Fig. 5 a The box plots (from top to bottom: maximum, upper quartile, median, lower quartile, and minimum values separately; see $y$-coordinate) are given for total and partial temperature changes (see $x$-coordinate) over EA. b Stacked bar chart of the inter-model spread

larger spread in surface albedo feedback indicates that narrowing down the differences in simulating snow/ice covers over both high latitudes and altitude area is important for future warming projection over EA.

Next, we discuss how these three processes with large uncertainties contribute to WPU in each model. Figure $5 \mathrm{~b}$ displays the areal means of these partial temperature changes over EA, overlapped by WPU values shown by the dashed black line. Basically, water vapor and surface albedo feedback terms are in phase with WPU in each model while surface non-radiative processes act to counteract WPU. The inter-model spreads of cloud feedback and atmospheric dynamic terms are also not negligible, but less significantly correlated with WPU. The remained of partial temperature changes $(K)$ over EA. Presented are the areameans of the partial temperature changes shown in Fig. 2a, with MME values removed. The dashed black line corresponds to the sum of stacked color bars

two terms, external forcing and ozone, nearly show no spreads. The cross-model correlation analysis of the EAmean total temperature changes with partial temperature changes (see Table 2) reveals significant positive correlations of WPU with surface albedo $(r=0.69)$ and water vapor feedback $(r=0.91)$. Cloud feedback and atmospheric dynamic process are also positively correlated to WPU, but with smaller correlation coefficients. Surface non-radiative processes tend to counteract with WPU, showing a negative correlation with WPU. In addition, because of the small inter-model spreads of external forcing and ozone terms, the correlation results with these two terms listed in Table 2 should not be considered as an important contributor to WPU. 
Table 2 Coefficients of crossmodel correlation among the inter-model spreads in areamean total and partial surface temperature changes over EA

\begin{tabular}{lllllllll}
\hline & SUM & EXT & AL & WV & CLD & O3 & ATM & SRF \\
\hline SUM & 1.00 & -0.40 & $\mathbf{0 . 6 9}$ & $\mathbf{0 . 9 1}$ & 0.43 & 0.06 & 0.28 & -0.42 \\
EXT & - & 1.00 & -0.18 & -0.33 & $\mathbf{- 0 . 5 6}$ & -0.19 & 0.17 & 0.07 \\
AL & - & - & 1.00 & 0.47 & 0.20 & 0.10 & 0.35 & $-\mathbf{0 . 7 5}$ \\
WV & - & - & - & 1.00 & 0.27 & 0.19 & 0.27 & -0.32 \\
CLD & - & - & - & - & 1.00 & 0.22 & -0.17 & -0.29 \\
O3 & - & - & - & - & - & 1.00 & -0.25 & -0.23 \\
ATM & - & - & - & - & - & - & 1.00 & $-\mathbf{0 . 6 5}$ \\
SRF & - & - & - & - & - & - & - & 1.00 \\
\hline
\end{tabular}

The bold font denotes the correlation coefficients that are statistically significant at the $99 \%$ confidence level
We have applied the cross-model correlation analysis among the partial temperature changes to explore the possible relationship between different processes. As seen from Table 2, there is a significant negative correlation $(r=-0.75)$ between surface albedo feedback and surface non-radiative processes. Over land surface, large non-radiative energy changes are mostly caused by surface turbulent latent and sensible heat fluxes, as well as soil heat diffusion. Under global warming, the melting of snow/ice would lead to loss of both latent heat and sensible heat, damping the warming. The positive relationship between surface albedo and water vapor feedbacks reflects the moistening of air due to a stronger upward latent heat flux that provides additional amplification of surface warming on top of that due to the surface albedo feedback.

In short, from the perspective of areal means, WPU is mostly contributed by water vapor feedback, and secondly by surface albedo feedback, but suppressed by the dissipation through surface non-radiative processes.

\subsection{Spatial heterogeneity of WPU}

The spatial heterogeneity of WPU is investigated to gain a more comprehensive understanding of WPU. The subpanel in the upper left corner of Fig. 6 displays the patterns of cross-model standard deviations and the remaining panels of the figure show individual models' deviations from the MME values of surface warming projection, in a descending order based on the area-mean warmings over EA from left to right and top to bottom. Figures 7, 8, 9, 10 are the same as Fig. 6 but for the partial temperature changes associated with individual processes in association with surface albedo feedback, water vapor feedback, cloud feedback, and surface non-radiative processes.

The greatest standard deviations of warming projection are over the high latitudes and southern Tibetan Plateau where the most pronounced warming is located (Fig. 3a). This feature is consistent with the finding by Woldemeskel et al. (2015) who showed that uncertainty was relatively larger in colder regions. In proportion to the pattern of standard deviation, the models with greater averaged warming show large positive anomalies over the northwest of EA, and large negative anomalies for the models with weaker warming.

The standard deviation of the partial surface temperature change due to albedo feedback (the top left panel of Fig. 7) exhibits non-uniform spatial distribution with the greatest deviation in the similar locations of largest WPU. For most of the models with greater (smaller) warming, the spatial-mean inter-model spreads of surface albedo term are positive (negative) although it does not follow the order of the areal mean of WPU. The intermodel spreads of water vapor term show uniform standard deviation in space (top left panel in Fig. 8). For the individual inter-model spreads, the partial temperature changes associated with water vapor term almost share the same order of WPU, consistent with the result from correlation analysis (Table 2). Cloud feedback presents a standard deviation pattern resembling the MME pattern of its partial temperature change (top left panel in Fig. 9). The maximum of the spread is limited only in southern China, resembling the large value of MME partial surface temperature change due to cloud feedback, indicating the important role of cloud feedback in the climate change projection over southern China. Surface non-radiative processes tend to suppress the spatial heterogeneity caused by albedo and cloud feedbacks (Fig. 10). For example, models like GFDL-CM3 and BNU-ESM produce extremely strong albedo feedback (Fig. 7). Correspondingly, the strong surface non-radiative processes are coupled with the pronounced albedo feedback and exhibit an opposite sign. For CESM1-CAM5 and CMCC-CESM, the models with above-normal perturbations in cloud property, the surface non-radiative processes also act to partially offset the models' total deviation of surface temperature anomalies relative to the MME value.

To measure the relative contributions of different feedback processes to the magnitude and spatial distribution of 

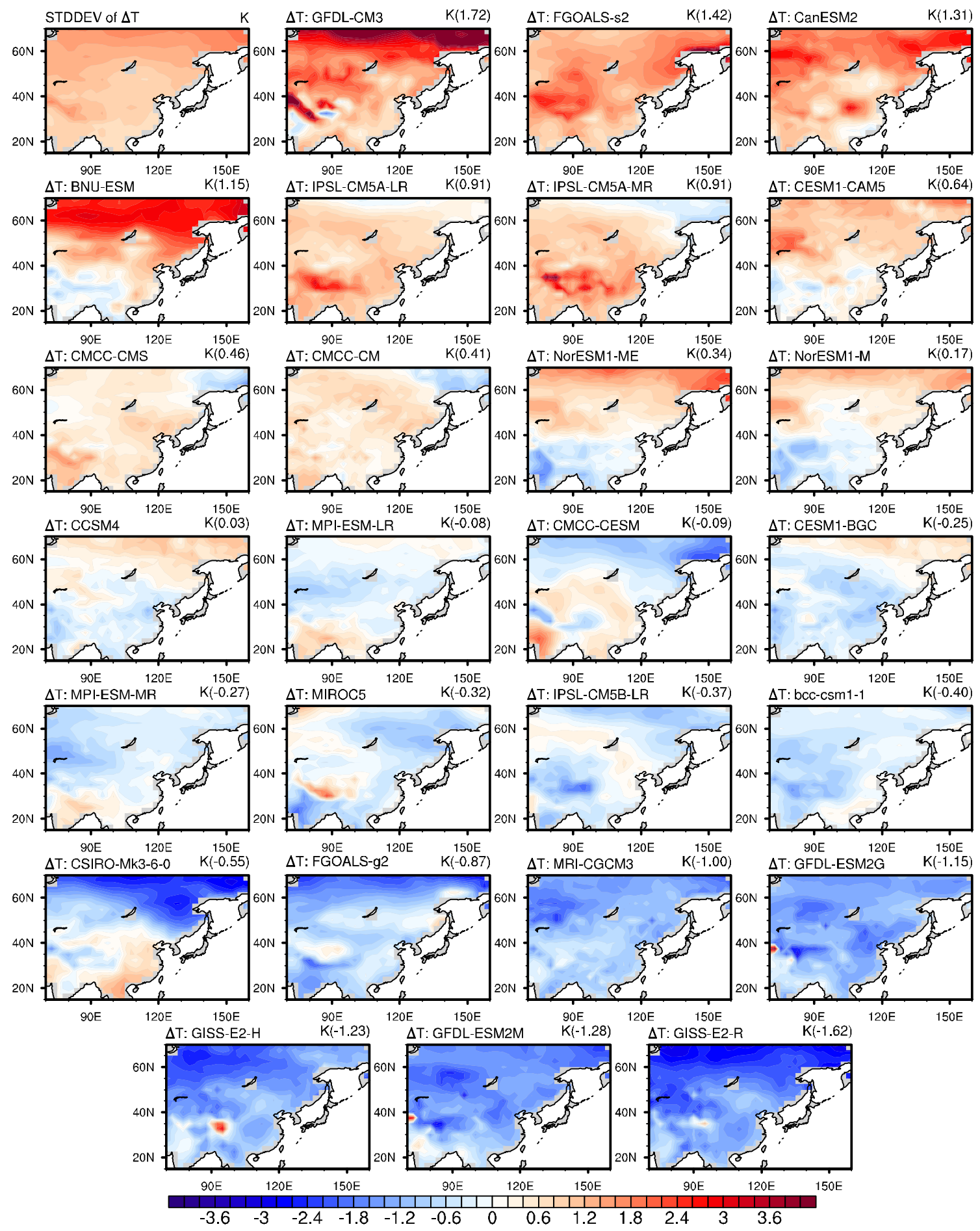

Fig. 6 Spatial patterns of the standard deviation of surface warming projection over EA under RCP8.5 scenario (the top-left panel) and the differences $(K)$ in surface warming between the MME and indi- vidual models. The values on the upper right of individual panels denote the corresponding area averaged values 

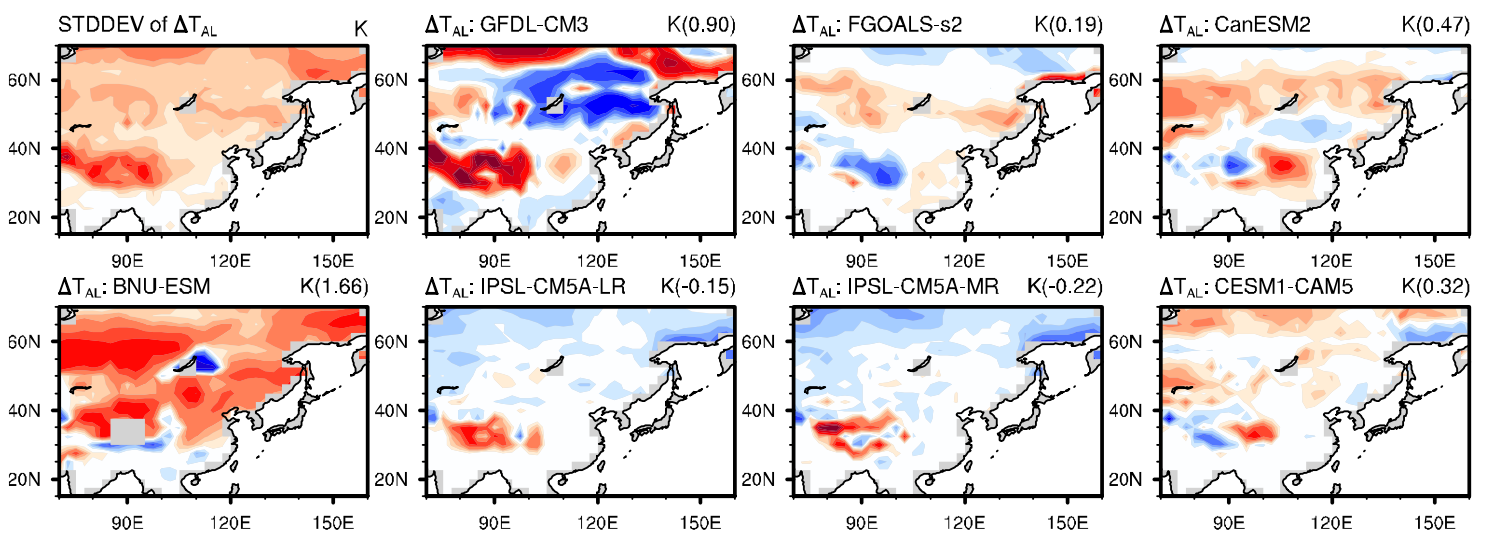

$\Delta \mathrm{T}_{\mathrm{AL}}$ : IPSL-CM5A-MR $\mathrm{K}(-0.22)$
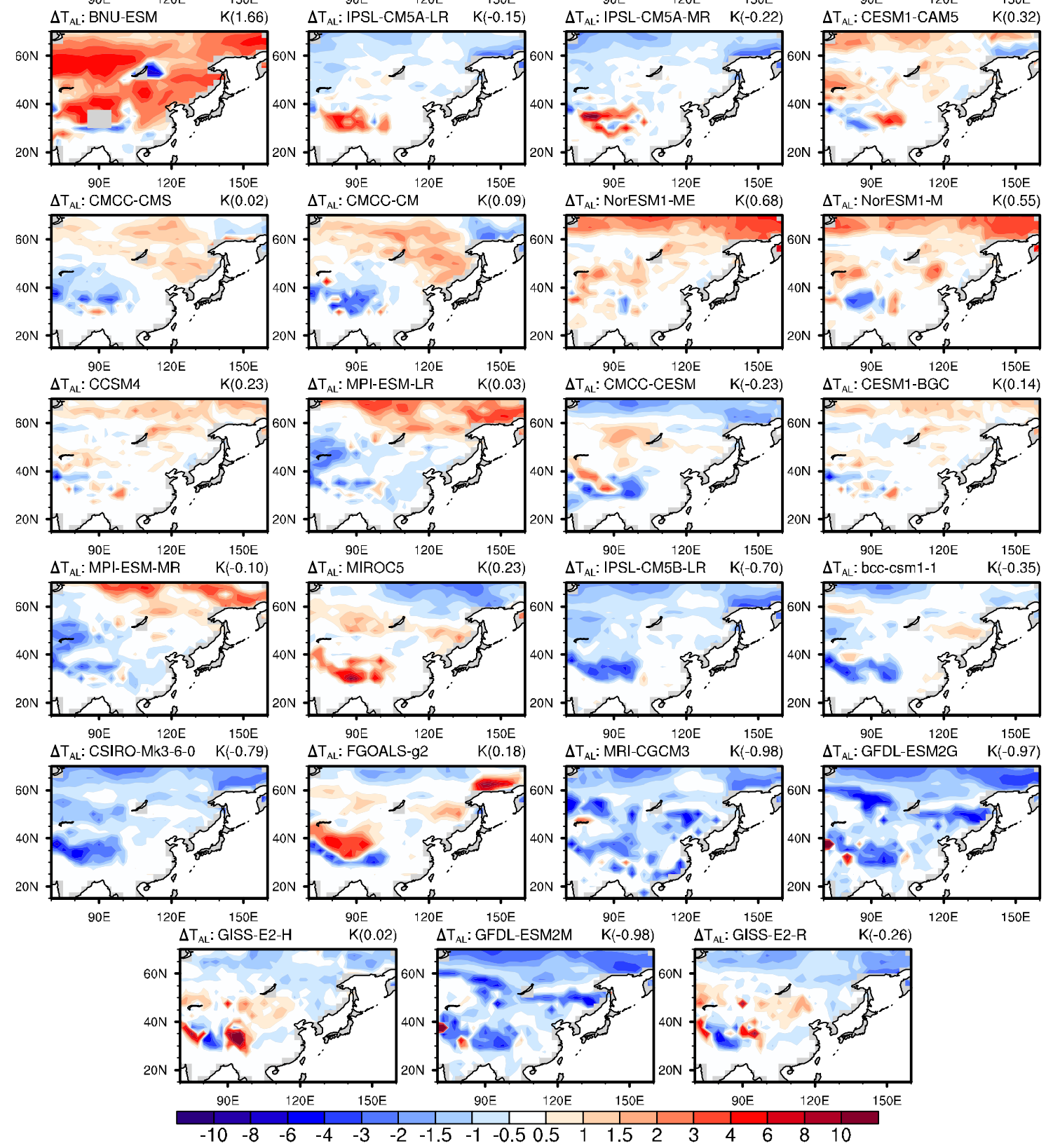

Fig. 7 Same as Fig. 6, but for partial surface temperature change due to surface albedo feedback 

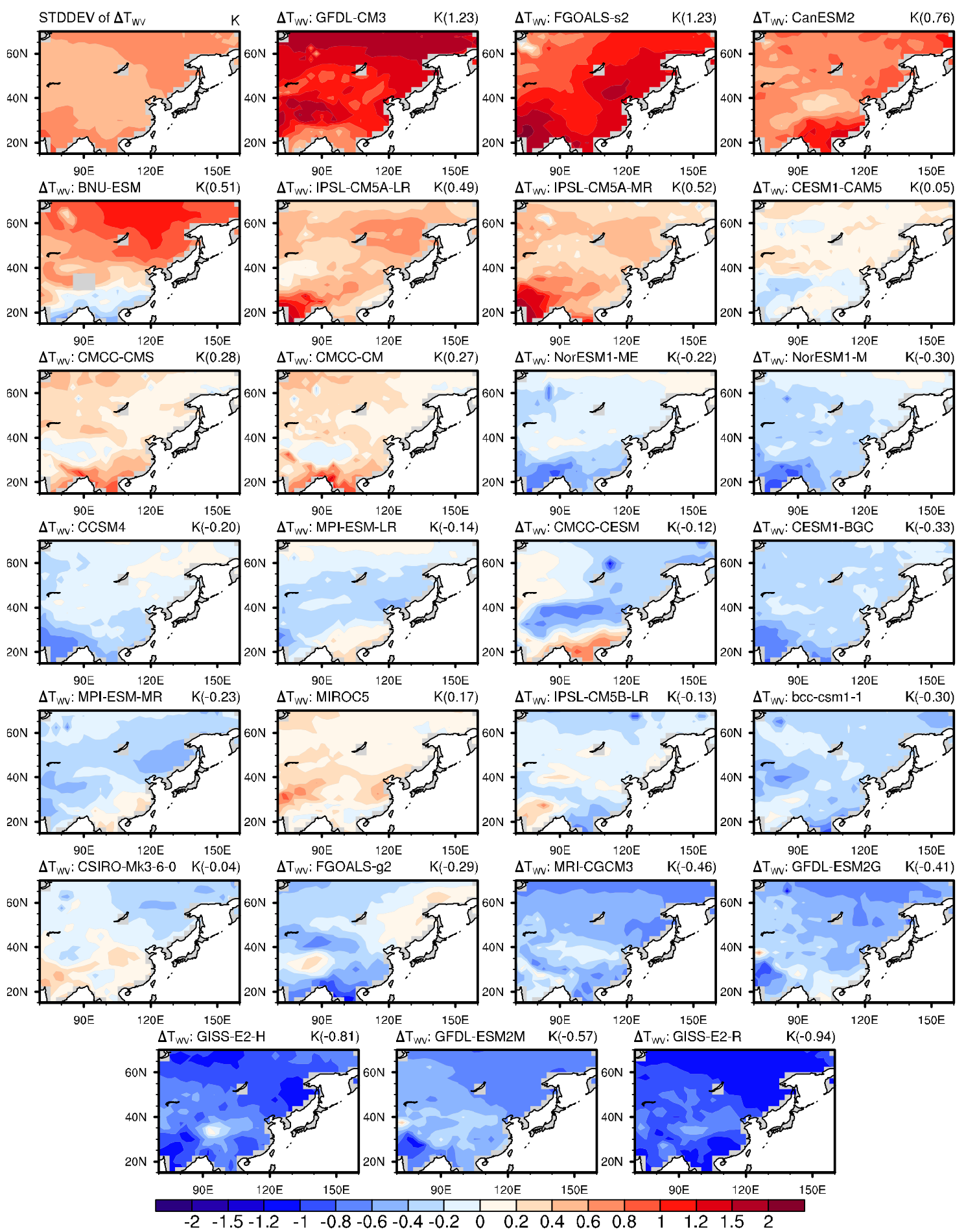

Fig. 8 Same as Fig. 6, but for partial surface temperature change due to water vapor feedback 

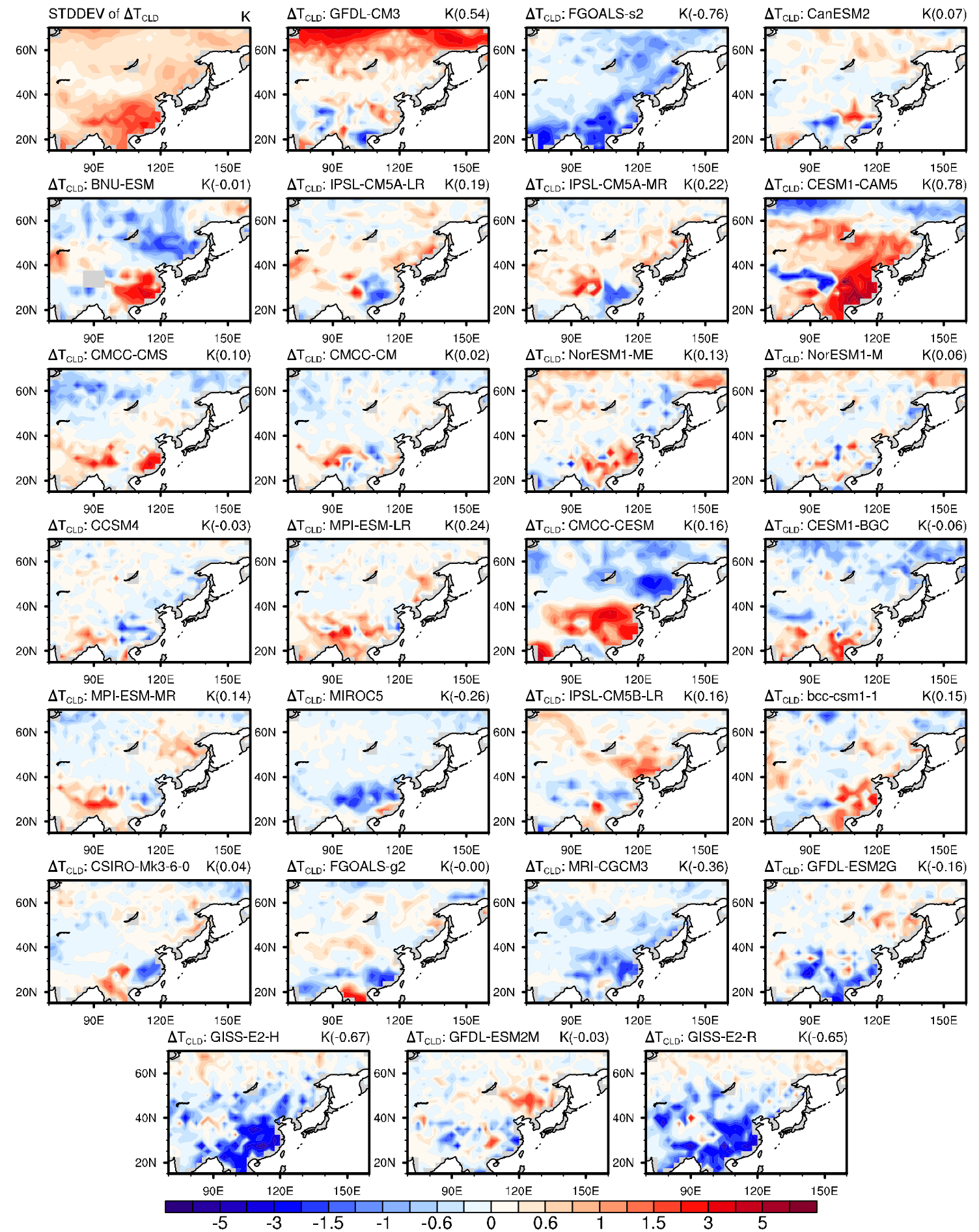

Fig. 9 Same as Fig. 6, but for partial surface temperature change due to cloud feedback 

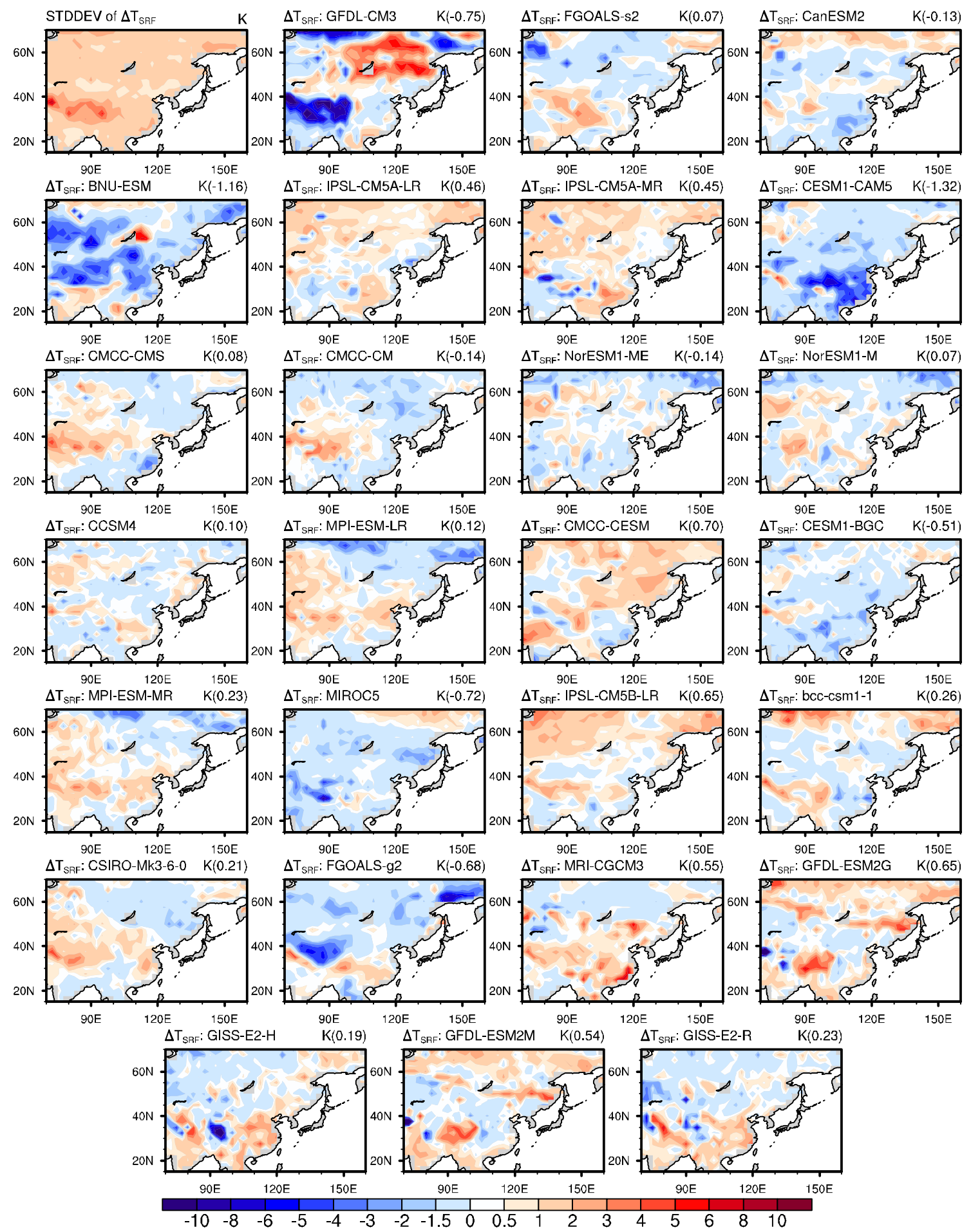

Fig. 10 Same as Fig. 6, but for partial surface temperature change due to surface processes (surface heat fluxes, surface dynamics and energy storage) 

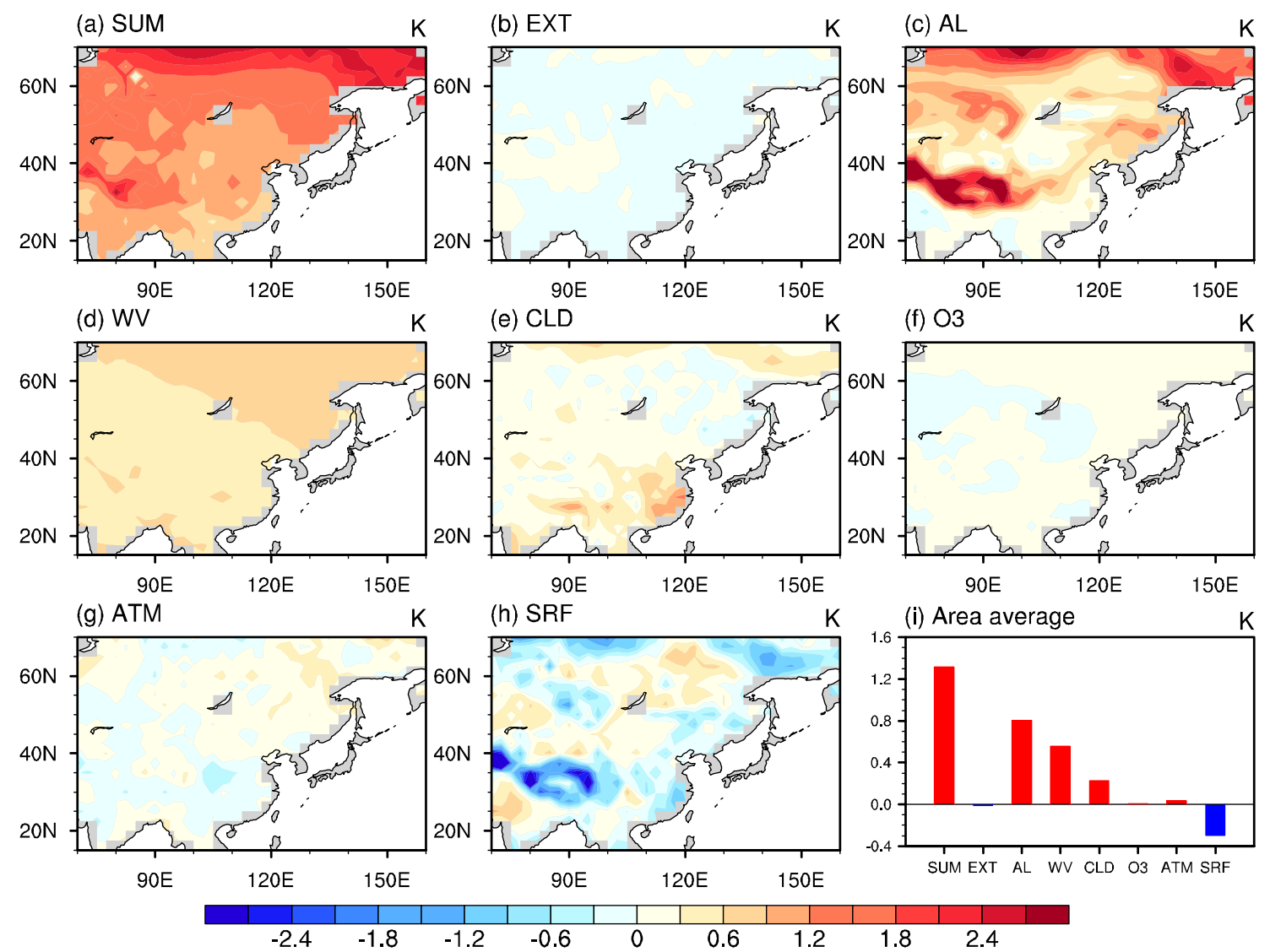

Fig. $11 \mathbf{a}$ is the sum of $(\mathbf{b}-\mathbf{h})$. $\mathbf{b}-\mathbf{h}$ show the spatial patterns of $\mathrm{CR}_{i}(K)$ due to individual external forcing and climate feedback processes. $\mathbf{i}$ The areal mean of $\mathrm{CR}_{i}$ as a summary of subpanels $(\mathbf{a}-\mathbf{h})$

WPU over EA, we define a contribution coefficient (CR) at each grid-point as the following:

$\mathrm{CR}_{i}=\frac{N^{-1}\left(\sum_{n=1}^{N} \Delta T_{n}^{i} \Delta T_{n}\right)}{\sqrt{N^{-1} \sum_{n=1}^{N} \Delta T_{n}^{2}}}$

where $\Delta T_{n}\left(\Delta T_{n}^{i}\right)$ denotes the $n$th model's deviation of total (CFRAM-derived partial) surface temperature change from the corresponding MME value. The superscript " $i$ " indicates the external forcing or individual internal climate feedback processes contributing to both the total surface temperature change and the WPU. A positive inter-model $\mathrm{CR}_{i}$ indicates that the process tends to enhance the WPU at the corresponding grid-point, and vice versa for a negative $\mathrm{CR}_{i}$. Moreover, the sum of $\mathrm{CR}_{i}$ over all terms approximately equals to the standard deviation of WPU $\left(\sum_{i} \mathrm{CR}_{i}=\sqrt{N^{-1} \sum_{n=1}^{N} \Delta T_{n}^{2}}, n=1,2, \ldots, 26\right)$.

The spatial patterns of $\mathrm{CR}_{i}$ and area-averaged values are shown in Fig. 11. It is seen that the sum of $\mathrm{CR}_{i}$ (Fig. 11a) displays a similar pattern to the standard deviation of the WPU (the top left panel in Fig. 6) with large values over the high latitudes and southern Tibetan Plateau, indicating relative larger uncertainty over these regions. Analysis of the results of individual processes shows that water vapor feedback yields a relatively homogeneous pattern (Fig. 11d), meaning that water vapor feedback makes little contribution to the spatial nonuniformity in spite of its dominant role in the area-mean WPU (Fig. 11i). However, surface albedo, cloud, and surface non-radiative feedbacks are the main contributors to the inhomogeneity of WPU. Specifically, over the high latitudes and southern Tibetan Plateau, albedo feedback shows extremely large positive $\mathrm{CR}_{i}$ (Fig. 11c), while the values of $\mathrm{CR}_{i}$ due to other processes are relatively small (Figs. 11b, d, f, g) or even negative (Fig. 11h). This feature indicates that albedo feedback is the dominant contributor to the WPU over these regions, although its contribution is weakened by surface dynamic processes and heat fluxes. Over southern China, the modest positive values of $\mathrm{CR}_{i}$ due to cloud feedback (Fig. 11e) suggest the inter-model spread of changes in cloud properties as the main contributor to the WPU over this region. Given the nearly uniform positive values of $\mathrm{CR}_{i}$ due to water vapor feedback and the weak negative values related to surface processes, the combined effect of the aforementioned three processes leads to a 
relatively smaller WPU over southern China compared with the other regions in EA.

Note that although water vapor feedback is less important for the formation of spatial distribution of WPU, its area-averaged $\mathrm{CR}_{i}$ ranks second to the value of albedo feedback and is significantly larger than that of cloud feedback (Fig. 11i). Thus, water vapor feedback plays an important role in the area-mean amplitude of WPU over EA. In addition, external forcing, ozone, and atmospheric dynamics show uniform patterns with small values (Figs. 11b, f, g), indicating small influences on the WPU.

Since the RCP scenario spread is also the source of WPU, we further examine the projected surface warming and changes in other variables over EA under the RCP4.5 scenario by the same 26 models (figures not shown). Under the RCP4.5 scenario, EA is also expected to experience greater warming and projection uncertainties than the globe just like the RCP8.5 scenario, although with relatively weaker net amplitudes. In general, all models in this work respond linearly to the amplitudes of external forcing, indicated by similarities between the two scenarios not only in the spatial pattern of changes in climate variables for individual models but also in the orders of the warming projection amplitudes by multi-models. Therefore, the results obtained from the RCP8.5 scenario are robust and can provide a clear picture in this study.

\section{Concluding remarks}

In this study, we have examined the sources of surface warming in the future climate state and warming projection uncertainty (WPU), with a focus on East Asia (EA). The projection of the surface warming is defined as the land surface temperature change under the RCP 8.5 scenario relative to the historical run in CMIP5 models. The WPU is the inter-model spread of warming projection by 26 models with the multi-model ensemble mean value removed. By conducting a climate feedback-response analysis method (CFRAM), we decomposed the projection of surface warming into partial surface temperature changes due to external forcing, radiative feedback processes in association with albedo, water vapor, and cloud feedbacks, and non-radiative processes including atmospheric dynamics and surface dynamics processes.

EA shows a stronger degree of warming and WPU than the global land-area mean as well as the global mean. External forcing and water vapor feedback are the major positive contributors to the warming projections, although with little difference in warming amplitude between the globe and EA. On the other hand, surface albedo feedback and surface nonradiative processes, which make weaker positive and negative contributions respectively, present obvious contrasts for the formation of warming amplitude differences between the global land and EA.

For the MME spatial patterns of total and partial temperature changes, external forcing and water vapor feedback induce nearly uniform warming. Surface albedo feedback induces greater warming over the high latitudes and highelevation regions in the northwest of EA due to the decrease in ice/snow accumulation. Dominated by the shortwave cloud effect at surface, the decrease in total cloud fractions under the RCP8.5 scenario induces surface warming mainly over southern China by allowing more insolate shortwave radiation to reach the surface. The pattern of partial temperature changes associated with surface non-radiative processes appears to be opposite to the patterns of surface albedo and cloud terms, suggesting that surface non-radiative processes suppress the spatial inhomogeneity caused by surface albedo and cloud feedbacks.

Analysis of the inter-model spreads of partial temperature changes can identify the sources of WPU and its spatial distribution features. We found that water vapor and surface albedo feedbacks are the major sources of area-mean WPU, while surface non-radiative processes seem to reduce WPU arisen from the surface albedo feedback. However, given the uniform spatial distribution of the standard deviation of partial temperature changes, water vapor feedback makes a limited contribution to the spatial distribution of projection uncertainty. The patterns of surface albedo, cloud feedbacks, and surface non-radiative processes show close relationships with the WPU, which emphasizes their contributions to the spatial distribution. The impacts of external forcing, ozone, and atmospheric dynamics on the WPU are small due to their uniform or small amplitudes.

It should be noted that the CFRAM analysis is conducted based on the principle of energy balance with two given different climate states, which in this study are the 50-year long-term means of historical and RCP8.5 simulations. In plain words, the CFRAM could not depict the detailed evolution of the climate system under greenhouse gas forcing and the causality of the feedback processes considered in the framework. However, the analysis provides an addable decomposition of temperature changes into process-based partial temperature changes with a good approximation, enabling us to efficiently understand the relative contributions of the radiative and non-radiative processes to the warming projection in each CMIP5 model as well as the remarkable inter-model uncertainty. Considering the complex annual cycle of the climate system over EA (e.g., monsoon system), the future study should apply monthly CFRAM analysis on the recently released CMIP6 data to further verify the seasonality of future warming projections.

Acknowledgements We are grateful for the constructive and insightful comments from the editor and the anonymous reviewers that 
have led to a significant improvement in the presentation. This study was supported by the National Key Research and Development Program of China (Grant 2016YFA0602703), the National Natural Science Foundation of China (Grants 4191101062, 41805050, 41690123, 41690120, and 41975074), the Natural Science Foundation of Guangdong Province (Grant 2018A0303130268), the Basic Science Research Program through the National Research Foundation of Korea (NRF) funded by the Ministry of Education (2018R1A6A1A08025520), and under the framework of international cooperation program managed by the National Research Foundation of Korea (2019K2A9A2A06020912), Guangdong Province Key Laboratory for Climate Change and Natural Disaster Studies (Grant 2020B1212060025), and supported by the Jiangsu Collaborative Innovation Center for Climate Change. Data used in this study are archived and freely accessible at http://data.ceda.ac.uk/badc/cmip5/data/cmip5/ and https://esgf-node.llnl.gov/search/cmip5/.

Open Access This article is licensed under a Creative Commons Attribution 4.0 International License, which permits use, sharing, adaptation, distribution and reproduction in any medium or format, as long as you give appropriate credit to the original author(s) and the source, provide a link to the Creative Commons licence, and indicate if changes were made. The images or other third party material in this article are included in the article's Creative Commons licence, unless indicated otherwise in a credit line to the material. If material is not included in the article's Creative Commons licence and your intended use is not permitted by statutory regulation or exceeds the permitted use, you will need to obtain permission directly from the copyright holder. To view a copy of this licence, visit http://creativecommons.org/licenses/by/4.0/.

\section{References}

Baek HJ, Lee J, Lee HS et al (2013) Climate change in the 21st century simulated by HadGEM2-AO under representative concentration pathways. Asia-Pac J Atmos Sci 49:603-618. https://doi. org/10.1007/s13143-013-0053-7

Byers E, Gidden M, Leclere D et al (2018) Global exposure and vulnerability to multi-sector development and climate change hotspots. Environ Res Lett. https://doi.org/10.1088/1748-9326/aabf45

Cai M, Lu J (2009) A new framework for isolating individual feedback processes in coupled general circulation climate models. Part II: method demonstrations and comparisons. Clim Dyn 32:887-900. https://doi.org/10.1007/s00382-008-0424-4

Chen H, Sun J, Chen X, Zhou W (2012) CGCM projections of heavy rainfall events in China. Int J Climatol 32:441-450. https://doi. org/10.1002/joc.2278

Chen J, Deng Y, Lin W, Yang S (2017) A process-based assessment of decadal-scale surface temperature evolutions in the NCAR CCSM4's 25-year hindcast experiments. J Clim 30:6723-6736. https://doi.org/10.1175/JCLI-D-16-0869.1

Chen J, Deng Y, Lin W, Yang S (2018) A process-based decomposition of decadal-scale surface temperature evolutions over East Asia. Clim Dyn 51:4371-4383. https://doi.org/10.1007/s0038 2-017-3872-x

Christensen JH, Kanikicharla KK, Aldrian E, et al (2013) Climate phenomena and their relevance for future regional climate change. Clim Chang 2013 Phys Sci Basis Work Gr I Contrib to Fifth Assess Rep Intergov Panel Clim Chang 9781107057999:12171308. Doi: https://doi.org/10.1017/CBO9781107415324.028

Collins M, Arblaster J, Dufresne J-L, et al (2013) Long-term climate change: projections, commitments and irreversibility. Clim Chang 2013 Phys Sci Basis Work Gr I Contrib to Fifth Assess Rep
Intergov Panel Clim Chang 9781107057:1029-1136. Doi: https ://doi.org/10.1017/CBO9781107415324.024

Colman R (2003) A comparison of climate feedbacks in general circulation models. Clim Dyn 20:865-873. https://doi.org/10.1007/ s00382-003-0310-Z

Deng Y, Park TW, Cai M (2013) Radiative and dynamical forcing of the surface and atmospheric temperature anomalies associated with the northern annular mode. J Clim 26:5124-5138. https:// doi.org/10.1175/JCLI-D-12-00431.1

Diffenbaugh NS, Swain DL, Touma D, Lubchenco J (2015) Anthropogenic warming has increased drought risk in California. Proc Natl Acad Sci USA 112:3931-3936. https://doi.org/10.1073/ pnas. 1422385112

Fischer EM, Knutti R (2015) Anthropogenic contribution to global occurrence of heavy-precipitation and high-temperature extremes. Nat Clim Chang 5:560-564. https://doi.org/10.1038/nclimate2617

Fu Q, Liou KN (1992) On the correlated k -distribution method for radiative transfer in nonhomogeneous atmospheres. J Atmos Sci 49:2139-2156. https://doi.org/10.1175/15200469(1992)049\%3c2139:OTCDMF\%3e2.0.CO;2

Fu Q, Liou KN (1993) Parameterization of the radiative properties of cirrus clouds. J Atmos Sci 50:2008-2025. https ://doi.org/10.1175/1520-0469(1993)050\%3c2008:POTRP $\mathrm{O} \% 3 \mathrm{e} 2.0 . \mathrm{CO} ; 2$

Giorgi F (2010) Uncertainties in climate change projections, from the global to the regional scale. EPJ Web Conf 9:115-129. https://doi. org/10.1051/epjconf/201009009

Heo KY, Ha KJ, Yun KS et al (2014) Methods for uncertainty assessment of climate models and model predictions over East Asia. Int J Climatol 34:377-390. https://doi.org/10.1002/joc.3692

Hu X, Yang S, Cai M (2016) Contrasting the eastern Pacific El Niño and the central Pacific El Niño: process-based feedback attribution. Clim Dyn 47:2413-2424. https://doi.org/10.1007/s0038 2-015-2971-9

Hu X, Li Y, Yang S et al (2017) Process-based decomposition of the decadal climate difference between 2002-13 and 1984-95. J Clim 30:4373-4393. https://doi.org/10.1175/JCLI-D-15-0742.1

Hu X, Cai M, Yang S, Wu Z (2018) Delineation of thermodynamic and dynamic responses to sea surface temperature forcing associated with El Niño. Clim Dyn 51:4329-4344. https://doi.org/10.1007/ s00382-017-3711-0

Hu X, Fan H, Cai M et al (2020) A less cloudy picture of the intermodel spread in future global warming projections. Nat Commun 11:4472. https://doi.org/10.1038/s41467-020-18227-9

Ji Z, Kang S (2015) Evaluation of extreme climate events using a regional climate model for China. Int J Climatol 35:888-902. https://doi.org/10.1002/joc.4024

Jiang D, Wang H, Lang X (2004) East Asian climate change trend under global warming background. Chin J Geophys 47:675-681. https://doi.org/10.1002/cjg2.3536

Lee SM, Min SK (2018) Heat stress changes over East Asia under $1.5^{\circ}$ and $2.0^{\circ} \mathrm{C}$ global warming targets. J Clim 31:2819-2831. https:// doi.org/10.1175/JCLI-D-17-0449.1

Li L, Yang S, Zhu X, Wang Z, Tang H (2010) Evidence of warming and wetting climate over the Qinghai-Tibet Plateau. Arct, Antarct Alp Res 42:449-457

Lu J, Cai M (2009) A new framework for isolating individual feedback processes in coupled general circulation climate models. Part I: formulation. Clim Dyn 32:873-885. https://doi.org/10.1007/s0038 2-008-0425-3

Lu J, Cai M (2010) Quantifying contributions to polar warming amplification in an idealized coupled general circulation model. Clim Dyn 34:669-687. https://doi.org/10.1007/s00382-009-0673-x

Min SK, Legutke S, Hense A et al (2006) East Asian climate change in the 21 st century as simulated by the coupled climate model 
ECHO-G under IPCC SRES scenarios. J Meteorol Soc Jpn 84:126. https://doi.org/10.2151/jmsj.84.1

Min SK, Son SW, Seo KH et al (2015) Changes in weather and climate extremes over Korea and possible causes: a review. AsiaPac J Atmos Sci 51:103-121. https://doi.org/10.1007/s1314 3-015-0066-5

Park TW, Deng Y, Cai M et al (2013) A dissection of the surface temperature biases in the Community Earth System Model. Clim Dyn 43:2043-2059. https://doi.org/10.1007/s00382-013-2029-9

Pithan F, Mauritsen T (2014) Arctic amplification dominated by temperature feedbacks in contemporary climate models. Nat Geosci 7:181-184. https://doi.org/10.1038/ngeo2071

Qu X, Huang G, Zhou W (2014) Consistent responses of East Asian summer mean rainfall to global warming in CMIP5 simulations. Theor Appl Climatol 117:123-131. https://doi.org/10.1007/s0070 4-013-0995-9

Romanovsky VE, Drozdov DS, Oberman NG et al (2010) Thermal state of permafrost in Russia. Permafr Periglac Process 21:136155. https://doi.org/10.1002/ppp.683

Rose B, Rayborn L (2016) The effects of ocean heat uptake on transient climate sensitivity. Curr Clim Chang Rep 2:190-201. https://doi. org/10.1007/s40641-016-0048-4

Sejas SA, Cai M, Hu A et al (2014) Individual feedback contributions to the seasonality of surface warming. J Clim 27:5653-5669. https ://doi.org/10.1175/JCLI-D-13-00658.1

Seo YW, Kim H, Yun KS et al (2014) Future change of extreme temperature climate indices over East Asia with uncertainties estimation in the CMIP5. Asia-Pac J Atmos Sci 50:609-624. https://doi. org/10.1007/s13143-014-0050-5

Serreze MC, Walsh JE, Chapin FS III et al (2000) Observational evidence of recent change in the northern high-latitude environment. Clim Change 46:159-207

Shukla J, DelSole T, Fennessy M et al (2006) Climate model fidelity and projections of climate change. Geophys Res Lett 33:L07702. https://doi.org/10.1029/2005GL025579

Taylor KE, Stouffer RJ, Meehl GA (2012) An overview of CMIP5 and the experiment design. Bull Am Meteorol Soc 93:485-498. https ://doi.org/10.1175/BAMS-D-11-00094.1
Vial J, Dufresne JL, Bony S (2013) On the interpretation of intermodel spread in CMIP5 climate sensitivity estimates. Clim Dyn 41:3339-3362. https://doi.org/10.1007/s00382-013-1725-9

Wang L, Chen W, Zhou W (2014) Assessment of future drought in Southwest China based on CMIP5 multimodel projections. Adv Atmos Sci 31:1035-1050. https://doi.org/10.1007/s0037 6-014-3223-3

Woldemeskel FM, Sharma A, Sivakumar B, Mehrotra R (2016) Quantification of precipitation and temperature uncertainties simulated by CMIP3 and CMIP5 models. J Geophys Res Atmos 121:3-17. https://doi.org/10.1002/2015JD023719

Xin X, Zhang L, Zhang J et al (2013) Climate change projections over East Asia with BBC_CSM1.1 climate model under RCP scenarios. J Meteorol Soc Jpn 91:413-429. https://doi.org/10.2151/ jmsj.2013-401

Xu Z, Fan K (2019) Projected changes in summer water vapor transport over East Asia under the $1.5^{\circ} \mathrm{C}$ and $2.0^{\circ} \mathrm{C}$ global warming targets. Atmos Ocean Sci Lett 12:124-130. https://doi.org/10.1080/16742 834.2019.1569869

$\mathrm{Xu}$ Y, Zhou BT, Wu J et al (2017) Asian climate change under 1.5-4 ${ }^{\circ} \mathrm{C}$ warming targets. Adv Clim Chang Res 8:99-107. https://doi. org/10.1016/j.accre.2017.05.004

Yang D, Kane DL, Hinzman LD et al (2002) Siberian Lena River hydrologic regime and recent change. J Geophys Res Atmos 107:1-10. https://doi.org/10.1029/2002JD002542

Yuan X, Wang L, Wu P et al (2019) Anthropogenic shift towards higher risk of flash drought over China. Nat Commun 10:1-8. https://doi. org/10.1038/s41467-019-12692-7

Zhu Y, Wang H, Zhou W, Ma J (2011) Recent changes in the summer precipitation pattern in East China and the background circulation. Clim Dyn 36:1463-1473. https://doi.org/10.1007/s0038 2-010-0852-9

Publisher's Note Springer Nature remains neutral with regard to jurisdictional claims in published maps and institutional affiliations. 